\title{
Dual contraception method utilization and associated factors among sexually active women on antiretroviral therapy in Gondar City, northwest, Ethiopia: a cross sectional study
}

Fewuze Abay ${ }^{1}$, Hedija Yenus Yeshita', Fantahun Ayenew Mekonnen ${ }^{2}$ and Mekonnen Sisay ${ }^{3^{*}}$

\begin{abstract}
Background: Mother to child transmission is responsible for $90 \%$ of child infection with human immune deficiency virus (HIV). Dual contraceptive use is one of the best actions to prevent mother's human immune deficiency virus transmission to her child and partner. This study aimed at assessing the prevalence and factors associated with dual contraceptive use among sexually active women on antiretroviral therapy in Gondar City, northwest, Ethiopia.

Methods: An institution based cross sectional study was conducted in Gondar City public health facilities from December 1 to 31, 2018. Systematic random sampling technique was utilized to include 563 study participants. Data were collected by interview using a structured questionnaire. Descriptive analysis was made to compute mean, median and proportion. Finally, multivariable logistic regression model was fitted to identify the factors associated with dual contraceptive method utilization. Analysis was performed by using Statistical Package for Social Sciences (SPSS) software version 20.

Results: The overall prevalence of dual contraceptive method utilization among sexually active women on antiretroviral therapy was $28.8 \%$ (95\% Cl: $24.9,32.7)$. Women aged 35-49 years (Adjusted odds ratio (AOR): $6.99 ; 95 \%$ Cl: $3.11,15.71)$ ), who lived in urban areas (AOR: $4.81 ; 95 \% \mathrm{Cl}: 2.04,11.31$ ), attended secondary and above education (AOR: 4.43; 95\% Cl: 1.92, 10.22), and disclosed HIV status to sexual partners (AOR: 9.84; 95\% Cl: 3.48, 27.81) were more likely to use dual contraceptive method.

Conclusion: In this study, the proportion of women who utilized dual contraceptive method was low. Age, place of residence, educational status and disclosure of HIV status were factors associated with dual contraceptive use. Therefore, providing education about the advantages of disclosing HIV status to sexual partners and strengthening of counseling about the advantages of dual contraceptive use will be helpful in enhancing the use of dual contraceptive method among sexually active women on antiretroviral therapy.
\end{abstract}

Keywords: Dual contraceptive utilization, Women on antiretroviral therapy, Gondar, Ethiopia

\footnotetext{
* Correspondence: mekudesu@gmail.com

${ }^{3}$ Department of Human Nutrition, Institute of Public Health, College of

Medicine and Health Sciences, University of Gondar, Gondar, Ethiopia

Full list of author information is available at the end of the article
}

(c) The Author(s). 2020 Open Access This article is distributed under the terms of the Creative Commons Attribution 4.0 International License (http://creativecommons.org/licenses/by/4.0/), which permits unrestricted use, distribution, and reproduction in any medium, provided you give appropriate credit to the original author(s) and the source, provide a link to the Creative Commons license, and indicate if changes were made. The Creative Commons Public Domain Dedication waiver (http://creativecommons.org/publicdomain/zero/1.0/) applies to the data made available in this article, unless otherwise stated. 


\section{Background}

According to 2015 Global statistics, 36.7 million people were living with human immune deficiency virus (HIV) worldwide [1], of whom, reproductive age group contributed $75 \%$ of the burden [2]. The problem is highest among people residing in Sub Saharan Africa where, $60 \%$ of people reported to live with human immune deficiency virus/acquired immune deficiency syndrome (HIV/AIDS) and more than half of them were females [3]. In Ethiopia, the total number of people living with HIV was documented to be 769, 600 in 2014. Of these, about $60 \%$ were females [4].

HIV/AIDS continues to have disastrous medical, economic, social, and physical impacts on individuals, females, nations and global community at large [5]. Globally, more than 2 million HIV positive women become pregnant every year due to poor contraceptive utilization and unsafe sex practices, out of which, 600, 000 die due to pregnancy related complications [6]. Unintended pregnancies accounted for $21.3 \%$ of new paediatric HIV infections [7], 90\% were from Sub Saharan Africa [8]. Ethiopia is one of the countries severely affected by the disease with over 100, 000 pregnancies tested positive for HIV and over 12, 000 HIV positive births annually [9]. Unintended pregnancies among HIV infected women contribute to poor maternal and child outcomes [10, 11].

In Sub Saharan Africa increasing the contraceptive prevalence rate (CPR) has been estimated to reduce the proportion of infants infected with HIV by $35-55 \%$ through reduction in primary HIV infection and unintended pregnancies in HIV infected women [12]. This reduction rate can be possible through exercising consistent use of male condom alone which can protect both unwanted pregnancies and sexually transmitted infections (STIs)/HIV at the same time [13]. However, using it alone as a contraceptive method is not a guarantee to be protected from unwanted pregnancy since inconsistent and improper use is the common practice [14]. For example, about $15 \%$ of a one-year cumulative incidence of unintended pregnancy had occurred as a result of using it alone [15]. To add more, among those who had routine use of condom alone, about 14 to $21 \%$ of them got pregnant during the first year [14, 16].

Even though, HIV-positive women can use other hormonal and non-hormonal contraceptive methods rather than male condom for preventing pregnancy, these methods do not protect partners against the transmission of both STIs/HIV between them [15, 17]. Consequently, it is true that there is no a single type of contraceptive method which is effective at preventing both unintended pregnancies and STIs/HIV at a time. Thus, dual-contraceptive method use is the most effective approach and strategy to effectively prevent both unwanted pregnancies and STIs/HIV simultaneously $[18,19]$.

Dual contraceptive method use is the use of two different types of contraceptive methods, a barrier contraceptive along with another family planning method which can reduce transmission of STIs/HIV and prevent pregnancy respectively $[20,21]$. Evidences show that 40 and $80 \%$ of unplanned pregnancies and abortions would be prevented if half and all of them who were using one type of contraceptive alone started using dual methods [22]. An intervention based study had also demonstrated that participants who adhered to dual method use had lower rates of unintended pregnancy at 24 months [23].

Apart from its effectiveness, its utilization is low particularly in developing countries including Ethiopia [24-28]. Several recent studies conducted in different parts of Ethiopia have examined dual contraceptive method use among HIV positive women and reported low utilization. A study done at the University of Gondar hospital, northwest Ethiopia, a study conducted in selected public hospitals of northern Ethiopia and another study done in Gebretsadik Shawo hospital, southwest Ethiopia found out that about 13.2, 15.7 and $19.8 \%$ of HIV positive women who were attending antiretroviral therapy (ART) clinics used dual contraceptive method, respectively [4, 29, 30].

Previous studies have reported that unmarried women [31], women who disclosed their HIV status to their partners, sero-discordant and no desire for more children [32-34] were more likely to use dual contraceptive method.

Currently, in Ethiopia, HIV transmission is high and is a public health problem. Many HIV positive women are still encountering unintended pregnancy with a concomitant risk of mother to child transmission (MTCT) of HIV, pregnancy related morbidity and mortality, and transmission of HIV and new strain of HIV virus to their sexual partners due to low dual contraceptive method utilization. Ethiopian national health policy and strategy encourage dual contraceptive method use as a key intervention to reduce HIV transmission and unintended pregnancy. In addition, Ministry of health of Ethiopia in collaboration with partners also developed the post 2015 objective of prevention of mother to child transmission (PMTCT) to consolidate \& sustain the elimination of MTCT and reduce the vertical transmission to less than $2 \%$ by 2020 . To ensure virtual elimination, one of the main focuses is improving the use of dual contraceptive method among HIV positive women by integrating family planning services with PMTCT [35]. However, there is no adequate evidence in Ethiopia, particularly in our study area, Gondar City.

Therefore, the results of the current work would be helpful by providing updated evidences regarding the prevalence of dual contraceptive method utilization and 
its associated factors which hinder and/or enhance its utilization among sexually active women on antiretroviral therapy (ART), in Gondar City, northwest Ethiopia to public health practitioners and policy makers to create programs and restructure the system to reach the target audiences.

\section{Methods}

\section{Study design and setting}

An institutional based cross sectional study was conducted from December 1 to 31, 2018 in Gondar City public health facilities with ART clinics. Gondar town is located in the Amhara regional State, Ethiopia at a distance of $747 \mathrm{~km}$ from Addis Ababa, the capital of Ethiopia. The City has a total population of 333, 103. About 2, 919 and 2, 152 reproductive age women were enrolled in ART clinics of Gondar referral hospital and Gondar City health centers, respectively [36, 37].

\section{Study population}

All randomly selected sexually active HIV positive women of reproductive age (15-49), who had follow up in the ART clinics of Gondar City health facilities were included in this study. Women who were pregnant, had hearing difficulties and/or with confirmed infecundity were excluded.

\section{Sample size determination and sampling procedure}

The sample size was determined by using single population proportion formula taking the assumptions of $32 \%$ dual contraceptive proportion (P) (28), 95\% confidence interval (CI), $4 \%$ margin of error (d) and a 10\% nonresponse rate using Epi-Info software version 7 which yielded 574 participants.

The estimated sample size was allocated to each health facility proportion to size of ART user women in the respective health facility. During the data collection period, there were a total of 1148 sexually active HIV positive women, of whom, 655 were from Gondar referral hospital and 295, 114, 47 and 37 were from Gondar, Azezo, Maraki and Teda health centers, respectively. Accordingly, $327 \quad\left(655^{*} 574 / 1148\right), \quad 148 \quad\left(295^{*} 574 / 1148\right), \quad 57$ (114*574/1148), $23\left(47^{*} 574 / 1148\right)$ and $19\left(37^{*} 574 / 1148\right)$ samples were proportionally taken from Gondar referral hospital, Gondar, Azezo, Maraki and Teda health centers, respectively. A systematic random sampling technique was used to select participants from each health facilities. Sampling interval (K) was determined by dividing the total number of pregnant women who were visiting the ART clinics by the estimated sample size; $\mathrm{K}=$ $1148 / 574=2$. The first participant was identified by lottery method from 1 and 2, and 2 was drawn as the first participant. Then, every 2 participants were selected from the sampling frame until the total sample size was achieved.

\section{Data collection procedures and quality control}

A structured questionnaire was used to collect the data (Additional file 1). It was composed of socio demographic and economic factors (age, marital status, residence, religion, woman's educational level, partner's educational level, woman's occupation, partner's occupation and income), sexual and reproductive factors (number of children, woman's desire to have children, partner's desire to have children and knowledge about contraceptive), and factors related to HIV and STI (CD4 cell count, duration of ART, viral load and history of STI, knowledge of partner's HIV status, HIV status disclosure to partner). The questionnaire was originally prepared in English and translated to Amharic and back to English to ensure consistency. Five diploma and two-degree holder nurses were recruited as data collectors and supervisors, respectively. The data were collected after a one-day training was given regarding interview techniques and ethical concerns. Chart review was done for medical records of participants, including confirmation of highly active antiretroviral therapy (HAART), duration of ART, STI history, CD4cell and viral load counts. The questionnaire was pretested on $5 \%$ of the total sample from similar participants outside of Gondar City. Then, necessary modifications were done to the questionnaire. The data collection process was closely supervised by the supervisors and principal investigator on a daily basis.

\section{Measurement of variables and operational definitions Dual contraceptive method use}

Utilization of any hormonal, intrauterine contraceptive device or permanent modern contraceptive method along with male or female condom for the last 1 month prior to the study period [38].

\section{Knowledge of contraceptive}

Respondents, who have heard of at least one contraceptive method [4, 39].

\section{Sexually active}

A client who engaged in sexual activity within 1 month prior to the survey [40].

\section{Data processing and analysis}

Data were coded, cleaned, and entered in to Epi-Info version 7, and then exported to SPSS software version 20 for analysis. Summary statistics of variables such as percentage, median and Inter Quartile Range (IQR) were calculated. Multivariable analysis was used to identify associated factors of dual contraceptive utilization. Effect size was presented by odds ratio (OR) with 95\% 
confidence interval and $p$-value. A predictor variable with $p$-value less than 0.05 was considered as having a statistically significant association with the dependent variable. Furthermore, model fitness was checked by Hosmer and Lemeshow goodness of fit-test $(p=0.35)$.

\section{Ethical considerations}

Ethical clearance was obtained from the Institutional Review Board of the University of Gondar. Permission letter was obtained from Gondar City Administration Health Office. Each health facility head was communicated through formal letter obtained from Gondar City Administration Health Office. Objectives of the study were explained to study participants. Written informed consent was obtained from participants, or parents/ guardians of participants for those whose ages were less than 18 years old. The confidentiality of information was guaranteed by using code numbers rather than personal identifiers and by keeping the data protected by locking. Participants were told that they could decline at any time if they feel uncomfortable, even after the interview has started.

\section{Results}

\section{Socio, demographic characteristics of respondents}

A total of 563 women on ART participated in this study with a response rate of $98 \%$. The remaining participants provided incomplete responses and were rejected from the analysis. The median age of the respondents was 31 (IQR; 26, 37) years. Half of the participants were found in the age category of 25-34 years. Below one fifth, 97 $(17.2 \%)$ and $184(32.7 \%)$ of the participants were in the age category of 35 and above and 15-24 years, respectively. About half, $282(50.1 \%)$ of them were also between 25 and 34 years. Regarding to their monthly income, 185 (32.9\%), 207 (36.8\%), $162(28.8 \%)$, and $9(1.6 \%)$ had > 2500, 1501-2500, 501-1500, and $<=500$ Ethiopian Birr, respectively.

Four hundred seventy-six (84.5\%) women were urban residents. The majority, 514 (91.3\%) and 546 (97\%), of the participants belong to Orthodox Christian religion and Amhara ethnic, respectively. Four hundred eightysix $(86 \%)$ women were married (Table 1$)$.

\section{Sexual and reproductive characteristics}

Regarding women's knowledge about contraceptive method, all, $563(100 \%)$ of study participants knew at least one method of contraception. The majority, 465 $(82.6 \%)$ of study participants and 359 (63.8\%) of women's sexual partners had no desire to have more children in the future.
Table 1 Socio- demographic characteristics of sexually active women on ART in public health facilities of Gondar City, northwest, Ethiopia, $2018(n=563)$

\begin{tabular}{|c|c|c|}
\hline Variables & Frequency (n) & Percent (\%) \\
\hline \multicolumn{3}{|l|}{ Age } \\
\hline $15-24$ & 97 & 17.2 \\
\hline $25-34$ & 282 & 50.1 \\
\hline$>=35$ & 184 & 32.7 \\
\hline \multicolumn{3}{|l|}{ Residence } \\
\hline Urban & 476 & 84.5 \\
\hline Rural & 87 & 15.5 \\
\hline \multicolumn{3}{|l|}{ Religion } \\
\hline Orthodox & 514 & 91.3 \\
\hline Muslim & 49 & 8.7 \\
\hline \multicolumn{3}{|l|}{ Marital status } \\
\hline Married & 486 & 86.3 \\
\hline Never married & 51 & 9.1 \\
\hline Divorced & 17 & 3.0 \\
\hline Separated & 9 & 1.6 \\
\hline \multicolumn{3}{|l|}{ Ethnicity } \\
\hline Amhara & 546 & 97.0 \\
\hline Tigray & 10 & 1.8 \\
\hline Other ${ }^{a}$ & 7 & 1.2 \\
\hline \multicolumn{3}{|l|}{ Women's education } \\
\hline No education & 245 & 43.5 \\
\hline Primary education & 183 & 32.5 \\
\hline Secondary education & 94 & 16.7 \\
\hline Above secondary & 41 & 7.3 \\
\hline \multicolumn{3}{|l|}{ Husband's education } \\
\hline No education & 226 & 40.1 \\
\hline Primary education & 212 & 37.7 \\
\hline Secondary education & 107 & 19.0 \\
\hline Above secondary & 18 & 3.2 \\
\hline \multicolumn{3}{|l|}{ Woman's occupation } \\
\hline Student & 16 & 2.8 \\
\hline Merchant & 100 & 17.8 \\
\hline Government employee & 49 & 8.7 \\
\hline Housewife & 184 & 32.7 \\
\hline Daily laborer & 82 & 14.6 \\
\hline Private employee & 102 & 18.1 \\
\hline Other $^{b}$ & 30 & 5.3 \\
\hline \multicolumn{3}{|l|}{ Husband's occupation } \\
\hline Student & 3 & 0.5 \\
\hline Merchant & 122 & 21.7 \\
\hline Government employee & 78 & 13.9 \\
\hline Daily laborer & 144 & 25.6 \\
\hline
\end{tabular}


Table 1 Socio- demographic characteristics of sexually active women on ART in public health facilities of Gondar City, northwest, Ethiopia, $2018(n=563)$ (Continued)

\begin{tabular}{lll}
\hline Variables & Frequency $(\mathrm{n})$ & Percent (\%) \\
\hline \multicolumn{1}{c}{ Private employee } & 185 & 32.9 \\
Other $^{\mathrm{c}}$ & 31 & 5.5 \\
Income & & \\
$<=500$ & 9 & 1.6 \\
501,1500 & 162 & 28.8 \\
1501,2500 & 207 & 36.8 \\
$>2500$ & 185 & 32.9 \\
\hline
\end{tabular}

Note: Other ${ }^{\mathrm{a}}$ Oromo, ${ }^{\mathrm{b}}$ Farmer, No occupation, ${ }^{\mathrm{C}}$ Waitress, Farmer

\section{Clinical and HIV related factors}

Concerning their sexual partners' HIV status, more than two third, 403 (71.6\%) of them reported to aware their partners' HIV status. The majority, 393 (69.8\%) of women disclosed their HIV status to their sexual partners. Of all participants, only 34 (6\%) of them had history or symptom of other STIs in the past 1 year, 30 $(88.2 \%)$ of whom received treatment (Table 2 ).

\section{Dual contraceptive method utilization}

This study showed that $162(28.8 \%)$ of the study participants (sexually active HIV positive women), used dual contraceptive method in the past 1 month prior to the survey. All, $563(100 \%)$ of the study participants reported using at least one modern contraceptive method. Of them, $386(68.6 \%)$ used condom and $200(35.5 \%)$ used dual contraceptive method. Twenty-five (4.4\%) used condom only. The most common methods used along with condom were, injectable 112 (69\%), pills 25 (15\%), implants $22(14 \%)$ and Intra Uterine Contraceptive Device (IUCD) 3 (2\%).

\section{Factors associated with dual contraceptive use}

Both bivariable and multivariable binary logistic regression models were used to conduct the crude and adjusted odds ratios with their 95\% confidence intervals (CI) and $p$-values. Accordingly, the result of bivariable analysis showed that age, residence, and educational status of the woman, occupation of partner, knowledge of partner's HIV status, HIV status of the partner and disclosure of HIV status to sexual partner were associated with dual contraceptive utilization. However, in multivariable logistic regression analysis, age, residence, educational status of the woman, and disclosure of HIV status to sexual partner were statistically significantly associated with dual contraceptive utilization.

Consequently, women in the age group of 35-49 years were 7 times more likely to use dual contraceptive method than those in the age group of 15 to 24 years (AOR: 6.99; 95\% CI: 3.11, 15.71). Similarly, women who
Table 2 Clinical and HIV related characteristics of sexually active women on ART in public health facilities of Gondar City, northwest Ethiopia, 2018

\begin{tabular}{|c|c|c|}
\hline Variables & Frequency (n) & Percent (\%) \\
\hline \multicolumn{3}{|l|}{ STI history } \\
\hline No & 529 & 94.0 \\
\hline Yes & 34 & 6.0 \\
\hline \multicolumn{3}{|c|}{ Know HIV status of partner } \\
\hline No & 160 & 28.4 \\
\hline Yes & 403 & 71.6 \\
\hline \multicolumn{3}{|l|}{ Partner's HIV status } \\
\hline Negative & 164 & 40.7 \\
\hline Positive & 239 & 59.3 \\
\hline \multicolumn{3}{|l|}{ Disclosed HIV status } \\
\hline No & 170 & 30.2 \\
\hline Yes & 393 & 69.8 \\
\hline \multicolumn{3}{|l|}{ Duration on ART (Years) } \\
\hline 0,1 & 44 & 7.8 \\
\hline 2,3 & 134 & 23.8 \\
\hline 4,5 & 75 & 13.3 \\
\hline 6,7 & 142 & 25.2 \\
\hline 8,9 & 111 & 19.7 \\
\hline$>=10$ & 57 & 10.1 \\
\hline \multicolumn{3}{|l|}{ Current CD4 cell count } \\
\hline$<250$ & 97 & 17.2 \\
\hline 250,349 & 109 & 19.4 \\
\hline$>=350$ & 357 & 63.4 \\
\hline \multicolumn{3}{|l|}{ Current viral load } \\
\hline Not high viral load & 526 & 93.4 \\
\hline High viral load & 37 & 6.6 \\
\hline
\end{tabular}

were urban residents were nearly 5 times more likely to use dual contraceptive method compared to their rural resident counterparts (AOR: 4.80; 95\% CI: 2.04, 11.31). Likewise, higher odds of dual contraceptive method utilization were observed among women who attended secondary and above education than those who attended lower education (AOR: 4.43; 95\% CI: 1.92, 10.22). Again, the odds of dual contraceptive method utilization were nearly 10 times higher among those who disclosed their HIV status to their sexual partners (AOR: 9.84; 95\% CI: 3.48, 27.81) (Table 3).

\section{Discussion}

This study was conducted to assess the proportion of dual contraceptive utilization and its associated factors among sexually active women on ART in Gondar City health facilities, northwest Ethiopia. The study revealed that, $28.8 \%$ (95\% CI: $24.9-32.7$ ) of sexually active women 
Table 3 Factors associated with dual contraceptive use among sexually active women on ART in public health facilities of Gondar City, northwest Ethiopia, 2018

\begin{tabular}{|c|c|c|c|c|c|}
\hline \multirow[t]{2}{*}{ Variable } & \multicolumn{2}{|c|}{ Dual contraceptive use $(n=563)$} & \multirow{2}{*}{$\begin{array}{l}\text { Crude OR } \\
(95 \% \mathrm{Cl})\end{array}$} & \multirow{2}{*}{$\begin{array}{l}\text { Adjusted OR } \\
(95 \% \mathrm{Cl})\end{array}$} & \multirow[t]{2}{*}{$P$-value } \\
\hline & Yes (\%) & No (\%) & & & \\
\hline \multicolumn{6}{|l|}{ Age (years) } \\
\hline 15,24 & $11(11.3)$ & $86(88.7)$ & 1 & 1 & \\
\hline 25,34 & $65(23)$ & $217(77)$ & $2.34(1.18,4.65)^{*}$ & $2.11(0.97,4.55)$ & 0.058 \\
\hline 35,49 & $86(46.7)$ & $98(53.3)$ & $6.86(3.44,13.71)^{*}$ & $6.99(3.11,15.71)^{* *}$ & $<0.001$ \\
\hline \multicolumn{6}{|l|}{ Residence } \\
\hline Urban & $154(32.4)$ & $322(67.6)$ & $4.72(2.23,10.02)^{*}$ & $4.8(2.04,11.31)^{* *}$ & $<0.001$ \\
\hline Rural & $8(9.2)$ & 79 (90.8) & 1 & 1 & \\
\hline \multicolumn{6}{|l|}{ Educational status of woman } \\
\hline No formal education & $51(20.8)$ & $194(79.2)$ & 1 & 1 & \\
\hline Primary education & $44(24)$ & $139(76)$ & $1.2(0.76,1.91)$ & $1.03(0.54,1.98)$ & 0.921 \\
\hline Secondary and above & $46(48.9)$ & $48(51.1)$ & $3.65(2.19,6.06)^{*}$ & $4.43(1.92,10.22)^{* *}$ & $<0.001$ \\
\hline \multicolumn{6}{|l|}{ Partner's occupation } \\
\hline Student & $1(33.3)$ & $2(66.7)$ & $0.53(0.04,6.51)$ & $2.5(0.14,46.11)$ & 0.537 \\
\hline Merchant & $31(25.4)$ & $91(74.6)$ & $0.36(0.16,0.82)^{*}$ & $0.72(0.26,1.98)$ & 0.53 \\
\hline Government employee & $21(26.9)$ & $57(73.1)$ & $0.39(0.17,0.93)^{*}$ & $0.59(0.20,1.73)$ & 0.337 \\
\hline Daily labor & $41(28.5)$ & $103(71.5)$ & $0.43(0.19,0.94)^{*}$ & $1.05(0.37,2.88)$ & 0.918 \\
\hline Private employee & $53(28.6)$ & $132(71.4)$ & $0.43(0.21,0.93)^{*}$ & $0.63(0.24,1.65)$ & 0.348 \\
\hline Other* & $15(48.4)$ & $16(51.6)$ & 1 & 1 & \\
\hline \multicolumn{6}{|c|}{ Aware of partner's HIV status } \\
\hline No & $7(4.4)$ & $153(95.6)$ & 1 & 1 & \\
\hline Yes & $155(38.5)$ & $248(61.5)$ & $13.66(6.24,29.91)^{*}$ & $2.69(1.01,7.31)$ & 0.051 \\
\hline \multicolumn{6}{|l|}{ Disclosure of HIV status } \\
\hline No & $6(3.5)$ & $164(96.5)$ & 1 & 1 & \\
\hline Yes & $156(39.7)$ & $237(60.3)$ & $17.99(7.77,41.65)^{*}$ & $9.84(3.48,27.81)^{* *}$ & $<0.001$ \\
\hline
\end{tabular}

Note: ${ }^{*}$ Crude OR, Significant at $P$ value $<0.05,{ }^{*}$ Adjusted OR, Significant at $P$ value $<0.05$

on ART used dual contraceptive method in the last month prior to the study. The factors identified to be significantly associated with dual contraceptive use were women's age, residence, educational status and disclosure of HIV status to sexual partner.

The proportion of dual contraceptive use in this study is consistent with the results of studies done in Fitche (32\%) and Addis Ababa (31\%), Ethiopia, and in Nigeria $(27.2 \%)$, and India (30\%) [10, 34, 41, 42]. But, the percentage of women using dual method is higher in our study compared to the findings of studies conducted in Tigray region (14\%), Mekelle public hospitals (15.7\%), and Gimbie town (17\%), Ethiopia and in Zambia (17.7\%) $[4,39,40,43]$. The observed variation between the studies might be due to the differences in socio demographic characteristics of participants included. Again, the inconsistency noted with studies from other countries may be attributable to socio demographic and cultural characteristics of study participants, study period and settings.
The proportion of women using dual method is lower in the present study compared to the findings of studies done in Tigray (59.9\%), Ethiopia, Kenya (38.5\%), and Nigeria (45\%) [32, 44, 45].. The discrepancy between study reports could probably be due to sociodemographic and cultural differences of the study populations, presence of quality, integrated sexual and reproductive health and ART services in Kenya and Nigeria.

According to our study results, older age women (35 to 49 years) were more likely to use dual contraceptive method than younger age women (15 to 24 years). The possible reason could be older age women might have better understanding the advantage of using dual contraceptives, in turn, making them use the method. In addition, there is an established evidence that as age advances the desire for more children in the future decreases. This finding suggested that providing due attention for younger age women is crucial to improve the utilization of dual contraceptive method among HIV positive women. This finding 
is in line with studies reported from southern part of Ethiopia, Uganda and Brazil [30, 33, 46].

Place of residence was one of the key determinants of dual contraceptive method utilization. This can be explained by the fact that urban residents are more exposed for better health information and technologies which might enable them to have a better decision power and free discussion with their sexual partners about utilization of family planning services than their rural counterparts. Furthermore, women living in urban areas are believed to have better physical access to contraceptives. Such explanation suggested the importance of enhancing counselling services focussing on rural women to increase the uptake of dual contraceptive method utilization. This evidence is supported by a study done in southern part of Ethiopia [30] which revealed that HIV positive urban women were more likely to use dual contraceptive method than rural women.

Higher proportion of dual contraceptive method utilization was observed among women who attended secondary and above education. This can be explained as women with high level of education might appreciate the advantages of dual contraceptive use, have higher levels of HIV/AIDS knowledge, able to discuss freely with their sexual partners and are less likely to have stigma towards HIV/AIDS, which, in turn, assists them to easily change their risky sexual behaviour. This result implied that the paramount contribution of women's education to improve dual contraceptive method utilization. Similar results were reported from Brazil and Uganda [33, 46].

This study also showed that disclosing own HIV status to sexual partner has been found to significantly increase utilization of dual contraceptive method. This may be due to the fact that women have common understanding about the importance of using dual contraceptive method and easily reach at consensus to use it. Moreover, disclosing HIV status fosters more open discussion with their sexual partners with regard to safe sexual practice and limiting number of children. As the study showed, disclosing their HIV status to their respective sexual partners is crucial to increase the coverage of dual contraceptive method among HIV positive women. This finding is supported by studies conducted in Mekelle and Addis Ababa, Ethiopia, Ghana, and Kenya [32, 40, 47, 48].

\section{Conclusion}

The proportion of sexually active HIV positive women who were using dual contraceptive method was low. Women's age, educational status, place of residence, and disclosure of HIV status to sexual partners were found to be significantly associated with dual contraceptive method utilization. Strengthening education of women on ART about the importance of disclosing own HIV status to sexual partner in particular and the advantage of using dual contraceptive in general is suggested for the prevention of the transmission of HIV to the child and sexual partner. Furthermore, encouraging and providing more attention for younger age, illiterate and rural women by health care providers and other concerned bodies is recommended.

\section{Limitations of the study}

This study tried to generate evidences on dual contraceptive utilization among HIV positive women. However, it cannot be free from some limitations. Due to the cross-sectional nature of the study design, temporal relationship could not be assessed. Since the issue is a sensitive one, this result may be prone to social desirability bias. In addition, variables such as social support awareness towards pregnancy and STDs, financial support, availability of services/supplies and involvement of association of people living with HIV/AIDS that might have been associated with dual contraceptive use were not included. Furthermore, the current study was health facility based, the result of this study may not be generalizable to those HIV positive mothers who were attending health institutions outside the study area and those who were in the community.

\section{Supplementary information}

Supplementary information accompanies this paper at https://doi.org/10. 1186/s12905-020-0890-3.

Additional file 1. Questionnaire (English Version Questionnaire).

\section{Abbreviations \\ AIDS: Acquired immune deficiency syndrome; AOR: Adjusted Odds Ratio; ART: Antiretroviral therapy; Cl: Confidence Interval; COR: Crude Odds Ratio; CPR: Contraceptive Prevalence Rate; HAART: Highly active antiretroviral therapy; HIV: Human immune deficiency virus; IQR: Inter Quartile Range; IUCD: Intra uterine contraceptive device; MTCT: Mother to child transmission; PMTCT: Prevention of mother to child transmission; SPSS: Statistical Package for Social Sciences; STI: Sexually transmitted infection}

\section{Acknowledgements}

We are very thankful for women for their willingness and time to participate in the study. We also would like to appreciate Gondar City Administration health office, health facility heads and health care providers for their support during data collection.

\section{Authors' contributions}

FA and KYY conceived the study, developed the tool, coordinated data collection, and carried out the statistical analysis and drafted the manuscript. FA, KYY, FAM and MS conceived the study, participated in the statistical analysis, and drafted the manuscript. FA, MS and FAM conceived the study and review the drafted manuscript. All authors read and approved the final manuscript.

\section{Funding}

The authors received no specific funding for this work.

Availability of data and materials

Data will be available upon request from the corresponding author. 


\section{Ethics approval and consent to participate}

Ethical clearance was obtained from the Institutional Review Board of the University of Gondar. Permission letter was obtained from Gondar City Administration Health Office. Each health facility head was communicated through formal letter obtained from Gondar City Administration Health Office. Objectives of the study were explained to study participants. Written informed consent was obtained from participants, or parents/guardians of participants for those whose ages were less than 18 years old. The confidentiality of information was guaranteed by using code numbers rather than personal identifiers and by keeping the data protected by locking. Participants were told that they could decline at any time if they feel uncomfortable, even after the interview has started.

\section{Consent for publication}

Not applicable.

\section{Competing interests}

The authors declare that they have no competing interests.

\section{Author details}

'Department of Reproductive Health, Institute of Public Health, College of Medicine and Health Sciences, University of Gondar, Gondar, Ethiopia. ${ }^{2}$ Department of Epidemiology and Biostatistics, Institute of Public Health, College of Medicine and Health Sciences, University of Gondar, Gondar, Ethiopia. ${ }^{3}$ Department of Human Nutrition, Institute of Public Health, College of Medicine and Health Sciences, University of Gondar, Gondar, Ethiopia.

Received: 21 September 2019 Accepted: 24 January 2020

Published online: 12 February 2020

\section{References}

1. UNAIDS, Fact sheet: global statistics. 2015.

2. Carpenter LM, Kamali A, Ruberantwari A, Malamba S, Whitworth JAG. Rates of HIV-1 transmission within marriage in rural Uganda in relation to HIV sero-status in rural Uganda in relation to the HIV sero-status of the partners. AIDS Behav. 1999:13:1083-9.

3. UNAIDS, AIDS. Epidemic update in united nation joint programme on HIV/ AIDS. Geneva: WHO/UNAIDS; 2011.

4. Melaku Y, Zeleke EG. Contraceptive utilization and associated factors among HIV positive women on chronic follow up care in Tigray Region, Northern Ethiopia: a cross sectional study. PLoS One. 2014;9(4).

5. UNAIDS WHO. Global Summary of AIDS Epidemic Report. Geneva: WHO 2007. p. 23-5.

6. Preventing HIV and unintended pregnancies: strategic framework 20112015 The Inter-agency Task Team for Prevention and Treatment of HIV Infection in Pregnant Women, Mothers, and their Children. 2012.

7. The Gap Report children and pregnant women living with HIV. 2015, USAID.

8. Global Update on the Health Sector Response to HIV. 2014, World Health Organization $(\mathrm{WHO})$

9. Reynolds H. Contraception to prevent HIV-positive births: current contribution and potential cost savings in PEPFAR countries. Sex Transm Infect. 2008;84:49-53.

10. Lawani L, Onyebuchi AK, lyoke C. Dual method use for protection of pregnancy and disease prevention among HIV-infected women in South East Nigeria. BMC Womens Health. 2014;14(1):39.

11. Heidi $R$, et al. The value of contraception to prevent perinatal HIV transmission. PubMed. 2006;33(6):350-6.

12. Chris O. Contraception in the context of HIV/AIDS. Afr J Reprod Health. 2012;16:1-25.

13. United Nations Population Fund and World Health Organization (WHO). Sexual and Reproductive Health ofWomen Living with HIV/AIDS: Guidelines on Care, Treatment and Support for Women Living with HIV/AIDS and Their Children in Resource-Constrained Settings. Geneva: WHO; 2006.

14. Trussell J. Contraceptive failure in the United States. Contraception. 2011; 83(5):397-404 PubMed Pubmed Central PMCID: 3638209, Epub 2011/04/12. eng.

15. Trussell J. Choosing a contraceptive: efficacy, safety, and personal considerations. In: Hatcher RA, Trussell J, Nelson AL, Cates Jr W, Stewart FH, Kowal D, editors. Contraceptive Technology. 19th ed. New York: Ardent Media; 2008
16. Fu H, Darroch JE, Haas T, Ranjit N. Contraceptive failure rates: new estimates from the 1995 National Survey of Family Growth. Fam Plann Perspect. 1999; 31(2):56-63 PubMed Epub 1999/05/04. eng.

17. Cates W Jr, Steiner MJ. Dual protection against unintended pregnancy and sexually transmitted infections: what is the best contraceptive approach? Sex Transm Dis. 2002:29(3):168-74.

18. Crosby RA, DiClemente RJ, Windgood GM, et al. Correlates of using dual methods for sexually transmitted diseases and pregnancy prevention among high-risk African-American female teens. J Adolesc Health. 2001;28: 410-4 [PubMed: 11336871].

19. Family Health International. Dual Protection: Best approach to recommend may vary. Network. 2003;22(4) Available at: http://www.fhi.org/en/RH/Pubs/ Network/v22 4/nt2244.htm. Retrieved November 6, 2010.

20. Dual protection against unwanted pregnancy and HIV / STDs. Sexual health exchange. 1998 (3):8. PubMed.

21. Wilson TE, Koenig LJ, Walter E, Fernandez I, Ethier K. Perinatal Guidelines Evaluation P. Dual contraceptive method use for pregnancy and disease prevention among HIV-infected and HIV-uninfected women: the importance of an event-level focus for promoting safer sexual behaviors. Sex Transm Dis. 2003;30(11):809-12 PubMed Epub 2003/11/07. eng.

22. Pazol K, Kramer MR, Hogue CJ. Condoms for dual protection: patterns of use with highly effective contraceptive methods. Public Health Rep. 2010; 125:208-17 [PubMed: 20297747].

23. Peipert JF, Redding CA, Blume JD, et al. Tailored intervention to increase dual-contraceptive method use: a randomized trial to reduce unintended pregnancies and sexually transmitted infections. Am J Obstet Gynecol. 2008; 198:630.e1-8 [PubMed: 18395692].

24. Magwali Thulani SM. Toms Harold, Brown Joelle, how are condoms used in a family planning setting: evidence from Zimbabwe. Cent Afr J Med. 2005; 51(7-8):79-84

25. Beyeza-Kashesya J, Ekstrom AM, Kaharuza F, Mirembe F, Neema S. My partner wants a child. A cross-sectional study of the determinants of the desire for children among mutually disclosed sero-discordant couples receiving care in Uganda. BMC Public Health. 2010:10:247.

26. Elul B, Delvaux T, Munyana E. Pregnancy desires and contraceptive knowledge and use among prevention of mother-to-child transmission clients in Rwanda. AIDS. 2009;23:S19-26. https://doi.org/10.1097/01.aids. 0000363774.91376.dc

27. Hoffman IF, Martinson FEA, Powers KA. The year-long effect of HIV-positive test results on pregnancy intentions contraceptive use and pregnancy incidence among Malawian women. J Acquir Immune Defic Syndr. 2008; 47(4):477-83.

28. Kakaire O, Kaye DK, Osinde MO. Contraception among persons living HIV with infection attending an HIV care and support Centre in Kabale Uganda. J Public Health Epidemiol. 2010;2(8):180-8.

29. Reta MM, Tessema GA, Shiferaw G. Prevalence of dual contraceptive use and associated factors among HIV positive women at University of Gondar Hospital, Northwest Ethiopia. BMC Res Notes. 2019;12:36 https://doi.org/10. 1186/s13104-019-4053.

30. Erashi MWM, Tesso FY, Beyene TT. Dual-Contraceptive Method Utilization and Associated Factors among HIV Positive Women Attending Art Clinic in Gebretsadik Shawo Hospital SNNPR South West Ethiopia. J Womens Health Care. 2015:4(6). https://doi.org/10.4172/2167-0420.1000267.

31. Pazol K, Kramer M, Hogue C. Condoms for dual protection patterns of use with highly effective contraceptive methods, in Public Health Report; 2010. p. 208-17.

32. Mulongo AM, Lihana RW, Githuku J, Gura Z. Factors associated with uptake of dual contraception among HIV-infected women in Bungoma County. Pan Afr Med J. 2017;28(Supp 1):2. https://doi.org/10.11604/pamj.supp.2017. 28.1.9289.

33. Kiyomi Tsuyuk RB, de Araujo Pinho A. Dual Protection and Dual Methods in Women Living with HIV. The Brazilian Context. J Sex Transm Dis. 2013;2013: 8.

34. Demissie DB, Girma T, Abdissa G. Dual contraceptive utilization and associated factors among people living with HIV attending ART clinic in Fitche Hospital Ethiopia. J Health Med Nurs. 2015:20:2422-8419.

35. The Federal Democratic Republic of Ethiopia, Ministry of Health. HIV/AIDS strategic plan 2015-2020 in an investment case approach, vol. 2014. Addis Ababa: Federal HIV/AIDS prevention and control office.

36. Gondar City Administration Office Report, 2018.

37. Health facilities ART follow up registration, 2018 
38. Federal Democratic Republic of Ethiopia Country Progress Report on HIV/ AIDS response. HIV/AIDS Prevention and Control Office (HAPCO). 2012.

39. Polisi A, Gebrehanna E, Tesfaye G, Asefa F. Modern contraceptive utilization among female ART attendees in health facilities of Gimbie town West Ethiopia. Reprod Health. 2014;11(30).

40. Gebrehiwot SW, Azeze GA, Robles CC, Adinew YM. Utilization of dual contraception method among reproductive age women on antiretroviral therapy in selected public hospitals of Northern Ethiopia. Reprod Health. 2017;14:125.

41. Tamene W. Desire and family planning demand among HIV positive men and women in follow up care in Addis Ababa antiretroviral treatment units; 2006. p. 65-72.

42. Chakrapani Venkatesan KT, Murali S, Peter N, Deborah C. Prevalence of and barriers to dual-contraceptive methods use among married men and women living with HIV in India. Infect Dis Obstet Gynecol. 2011.

43. Chibwesha C, Matoba CK, Mbewe R, Stringer J, Stringer E. Modern Contraceptive and Dual Method Use among HIV-Infected Women in Lusaka Zambia; 2011. p. 1-8.

44. Lawrence A, Joanne M, Eugene W, Grace D, Jumoke O. Promoting dual protection planning clinics in Ibadan Nigeria. Int Fam Plan Perspect. 2002; 28(2):87-95.

45. Berhane Y. Utilization of modern contraceptives among HIV positive reproductive age women in Tigray Ethiopia. A Cross Sectional Study. ISRN AIDS. 2013;2013. https://doi.org/10.1155/2013/319724.

46. Jolly B-K, Frank K, Mia EA, Stella N, Asli K, Florence M. To use or not to use a condom a prospective cohort study comparing contraceptive practices among HIV-infected and HIV-negative youth in Uganda. BMC Infect Dis. 2011;11:144.

47. Mekonnen AH, Gashe FE. Contraceptive use and method preference among HIV positive women in Addis Ababa Ethiopia a cross sectional survey. PubMed. 2014;14(1):566.

48. Rhoda W, Joseph M, Moses K, Nazarius T, Maria N. Fertility desires and unmet need for family planning among HIV infected individuals in two HIV clinics with differing models of family planning service delivery. BMC Women's Health. 2015;15:5. 10.1186/s12905-014-0158-x.

\section{Publisher's Note}

Springer Nature remains neutral with regard to jurisdictional claims in published maps and institutional affiliations.

Ready to submit your research? Choose BMC and benefit from:

- fast, convenient online submission

- thorough peer review by experienced researchers in your field

- rapid publication on acceptance

- support for research data, including large and complex data types

- gold Open Access which fosters wider collaboration and increased citations

- maximum visibility for your research: over $100 \mathrm{M}$ website views per year

At $\mathrm{BMC}$, research is always in progress.

Learn more biomedcentral.com/submissions 